\title{
Emotional Intelligence Level Higher in Residents Who Took a Gap Year Before Medical School
}

This article was published in the following Dove Press journal:

Advances in Medical Education and Practice

\author{
Ramzan Shahid' \\ William Adams $\mathbb{D}^{2}$ \\ 'Department of Pediatrics, Stritch School \\ of Medicine, Loyola University Chicago, \\ Maywood, Illinois, USA; ${ }^{2}$ Clinical \\ Research Office Biostatistics Core, \\ Loyola University Chicago, Maywood, \\ Illinois, USA
}

\begin{abstract}
Introduction: Emotional intelligence (EI) is the skill of understanding yourself, managing yourself, understanding others, and managing relationships. Studies have begun analyzing the level of EI demonstrated by resident physicians in various specialties. Very few studies have assessed EI levels of residents in multiple specialties within one institution. The purpose of our study was to assess the EI level of all residents at our institution and to determine which variables were associated with higher EI scores.

Methods: In 2018, residents voluntarily participated in the study by completing two online surveys. The first survey was a de-identified survey monkey asking demographic and other training information. The second survey was an online emotional intelligence survey assessing their EI skills, the Emotional Quotient Inventory 2.0 (EQ-i 2.0).

Results: A total of 176 of 486 residents (36.2\%) completed the study. There was no significant association between EI level and age, gender, type of medical degree, having an advanced degree, or being in a specific specialty. We found that residents who took time off before matriculating into medical school had higher overall EI scores than those who did not take time off $(p=0.02)$. Similarly, those who took time off before medical school scored higher in interpersonal skills $(p=0.04)$, empathy $(p=0.03)$, decision-making $(p=0.02)$, and impulse control $(\mathrm{p}=0.03)$.

Conclusion: Residents who had taken time off before matriculating in medical school had higher overall EI scores and higher scores in the EI components of interpersonal skill, empathy, decision-making, and impulse control.
\end{abstract}

Keywords: emotional intelligence, gap year, time off

\section{Introduction}

Emotional intelligence (EI) is a skill that is necessary for physicians to develop strong relationships with patients. EI is the ability to recognize and understand emotions in yourself and others, and the ability to use this awareness to manage your behavior and relationships. ${ }^{1}$ A physician's level of EI positively correlates with patients' trust, which in turn correlates with better patient follow-up, better doctor-patient relationships and increased patient satisfaction. ${ }^{2}$ EI is a key component in all clinical settings - from the board room and chairperson's office to the ward and bedside. ${ }^{3}$ Despite evidence that physicians can improve their EI, ${ }^{4}$ it is not commonly taught to physicians-in-training and little is known about factors that affect EI levels in residents.

Recently, studies have begun analyzing the level of emotional intelligence demonstrated by resident physicians in various specialties. ${ }^{4-8}$ These studies only looked at EI within certain specialties and have found varying levels of EI within
Correspondence: Ramzan Shahid Department of Pediatrics, Stritch School of Medicine, Loyola University Chicago, 2160 S. First Ave, Maywood, Illinois 60153, USA

Tel $+\mid 708-327-9125$

Fax + 708-327-9132

Email rshahid@lumc.edu
Advances in Medical Education and Practice 2020:1 I 559-562

DovePress f in $\mathbf{P}$ 
those specialties. However, very few studies have assessed EI levels of residents in multiple specialties within a single institution. The purpose of our study was to assess the EI level of all residents at our institution and to determine if factors such as age, sex, type of medical degree, having an advanced degree, and being in a specific specialty were associated with higher EI scores. We specifically wanted to look at whether taking time off before medical school had an impact on EI since many students thinking about matriculating medical school take a gap year ${ }^{9}$ and the literature suggests a gap year may enhance EI skills. ${ }^{10}$

\section{Materials and Methods}

All 486 residents at our tertiary university-affiliated hospital were asked to voluntarily participate in the study by completing two online surveys between February 2018 and April 2018. Residents from 20 specialties participated, including primary care specialties, surgical specialties, hospital-based specialties, and oral/dental programs.

Residents' emotional intelligence was assessed using the Bar-On Emotional Quotient Inventory 2.0 (EQ-i 2.0 ${ }^{\circledR}$ ), which is an online 133-item self-assessment instrument that uses a 5-point Likert scale to measure EI across five composite scales and 15 content subscales. ${ }^{11}$ All scores are standardized to a national mean of 100 with a standard deviation of 15. Responses were coded to minimize the loss of privacy and confidentiality and were paired with a demographic survey that captured residents' training specialty, type of medical degree (MD vs DO), other advanced degrees, and if they took time off during their education.

\section{Ethical Approval and Consent}

The study received full research and ethics approval No. LU-210530 from the Institutional Review Board of the Loyola University Health Sciences Division. All participants provided informed consent and the research was performed in accordance with the principles stated in the Declaration of Helsinki.

\section{Statistical Methods}

As part of their participation, residents were asked whether they "Went straight through from college to medical school to residency" or whether they "Took time off and worked along the way", "Took time off to do research along the way", or "took time to get an advanced degree". The primary aim was to compare emotional intelligence scores between residents who took any time off versus those who took no time off. For each composite EI score, an independent samples $t$-test was used to compare the average EI score between these two independent groups. The same approach was used to compare each EI sub-score while using a Sidak correction to control the Type 1 error rate. Independent samples $t$-tests were also used to assess whether emotional intelligence scores varied by sex and graduate degree status, while nonparametric Kruskal-Wallis tests were used to assess whether emotional intelligence scores varied by specialty training (ie, primary care, subspecialty, or non-physician) and type of medical school (ie, US allopathic, US osteopathic, dental or podiatry, or international training). For all analyses, the normal distribution assumption was assessed graphically using QQ plots and extreme observations were monitored using box plots. All analyses were completed using SAS version 9.4 (Cary, NC).

\section{Results}

One hundred seventy-six (36.2\% of 486$)$ residents completed the study. About half of the sample $(n=85$ or $48 \%)$ was male and about half was female $(n=91$ or $52 \%)$. Most participants completed their training at US allopathic $(\mathrm{n}=124$ or $70 \%)$ or US osteopathic $(\mathrm{n}=25$ or $14 \%$ ) schools, while far fewer completed their undergraduate training at an international medical school $(\mathrm{n}=16$ or $9 \%$ ), or dental or podiatry school ( $\mathrm{n}=11$ or $6.3 \%$ ). Most residents were in a subspecialty residency program $(\mathrm{n}=60$ or $34 \%)$ or primary care $(n=57$ or $32 \%)$ residency program, while far fewer were in some other residency program $(n=48$ or $27 \%)$ or were non-physicians $(n=11$ or 6.3\%). Among all participants, 46 (26\%) were PGY1, 47 (27\%) were PGY2, 50 (28\%) were PGY3, and 33 (19\%) were PGY 4-7. Twenty-nine (16\%) participants held a graduate degree. Overall, 97 (55\%) took some time off from their training, while 79 (45\%) took no time off.

In this sample, there was no significant association between EI level and sex, type of medical degree, having an advanced degree, or specific specialty (all $p>0.05$ ). However, compared to residents who took no time off, those who took time off from their training had higher overall EI scores $\left(M_{\text {diff }}=4.44,95 \%\right.$ CI: 0.68 to $8.20 ; p=$ $0.02)$. Similarly, those who took time off before medical school scored higher in interpersonal skills $\left(M_{\text {diff }}=4.03\right.$, 95\% CI: 0.19 to $7.86 ; p=0.04)$, empathy $\left(M_{\text {diff }}=5.01,95 \%\right.$ CI: 1.09 to $8.93 ; p=0.03)$, decision-making $\left(M_{\text {diff }}=4.68\right.$, 
95\% CI: 0.79 to $8.56 ; p=0.02)$, and impulse control $\left(M_{\text {diff }}=\right.$ 5.77, $95 \%$ CI: 1.54 to $10.00 ; p=0.03)$. See Table 1 .

\section{Discussion}

Many students take time off, a so-called gap year, before matriculating in medical school. National statistics show that $50-60 \%$ of medical school-minded students are taking at least one gap year. ${ }^{9}$

Students who take a gap year may benefit in a variety of ways. These can include learning to work with a more diverse array of people and working in larger groups, denoted often times as emotional intelligence. ${ }^{10}$ People with sound EI skills have the ability to communicate effectively, to build strong relationships, and to work as a team through collaboration and cooperation. ${ }^{12}$ A physician must be able to interact with patients, colleagues, and ancillary support staff in a way that will enhance patient care. EI skills may be the key to creating this type of environment.
Our study demonstrated residents who had taken time off before matriculating in medical school had higher overall EI scores and higher scores in the EI components of interpersonal skill, empathy, decision-making, and impulse control. These areas of higher scores could reflect the residents' experience during their time off. A gap year allows time for personal reflection, can help develop as a person, can increase maturity, can increase self-confidence, can help teach interactions with people from different backgrounds, and can help develop communication skills. ${ }^{13}$ One study of medical students found greater maturity, independence, life experience, and improved social interactions associated with taking gap year. ${ }^{14}$ These may be skills that allow residents to have higher EI compared to those who have not taken a gap year.

A limitation of our study is we do not ask for specific details regarding residents' time off, other than if they worked, did research, or got an advanced degree. Some residents may have done other activities during this time that could affect EI.

Table I Emotional Intelligence Score and Taking Time off

\begin{tabular}{|c|c|c|c|c|c|c|c|c|}
\hline & \multicolumn{6}{|c|}{ Took Time off } & \multirow[t]{3}{*}{$\mathbf{p}$} & \multirow[t]{3}{*}{ Sidak $\mathrm{p}$} \\
\hline & \multicolumn{2}{|c|}{ No $(n=79)$} & \multicolumn{2}{|c|}{ Yes $(n=97)$} & \multicolumn{2}{|c|}{ Total $(\mathbf{N}=176)$} & & \\
\hline & $\mathbf{M}$ & SD & $\mathbf{M}$ & SD & $\mathbf{M}$ & SD & & \\
\hline EI Total Score & 99.52 & 12.47 & 103.96 & 12.67 & 101.97 & 12.74 & 0.02 & - \\
\hline Self-Perception Composite & 100.46 & 12.27 & 103.93 & $1 \mathrm{I} .40$ & 102.37 & 11.89 & 0.054 & - \\
\hline Self-Regard & 96.32 & 13.50 & 99.36 & 12.23 & 97.99 & 12.87 & 0.12 & 0.32 \\
\hline Self-Actualization & 105.67 & 11.67 & 107.46 & 11.29 & 106.66 & 11.46 & 0.30 & 0.66 \\
\hline Emotional Self-Awareness & 99.20 & 12.30 & 103.65 & 14.12 & 101.65 & 13.48 & 0.03 & 0.09 \\
\hline Self-Expression Composite & 95.56 & 14.48 & 98.54 & 16.14 & 97.20 & 15.45 & 0.20 & - \\
\hline Emotional Expression & 98.56 & 16.37 & 99.86 & 16.88 & 99.27 & 16.62 & 0.61 & 0.94 \\
\hline Assertiveness & 97.35 & 13.69 & 98.25 & 15.98 & 97.85 & 14.96 & 0.69 & 0.97 \\
\hline Independence & 93.53 & 13.33 & 98.14 & 13.19 & 96.07 & 13.42 & 0.03 & 0.09 \\
\hline Interpersonal Composite & 103.63 & 13.10 & 107.66 & 12.58 & 105.85 & 12.94 & 0.04 & - \\
\hline Interpersonal Relationships & 100.97 & 12.54 & 103.24 & 14.02 & 102.22 & 13.38 & 0.27 & 0.61 \\
\hline Empathy & 103.54 & 14.15 & 108.56 & 12.20 & 106.31 & 13.31 & 0.01 & 0.03 \\
\hline Social Responsibility & 105.52 & 11.25 & 108.31 & $10.7 \mid$ & 107.06 & 11.01 & 0.09 & 0.25 \\
\hline Decision Making Composite & 99.58 & $12.9 \mid$ & 104.26 & 13.05 & 102.16 & 13.16 & 0.02 & - \\
\hline Problem Solving & 96.32 & 13.23 & 99.38 & 13.85 & 98.01 & 13.62 & 0.14 & 0.36 \\
\hline Reality Testing & 100.22 & 11.48 & 102.38 & 12.64 & 101.41 & 12.15 & 0.24 & 0.56 \\
\hline Impulse Control & 102.76 & 15.16 & 108.53 & 13.25 & 105.94 & 14.39 & 0.01 & 0.03 \\
\hline Stress Management Composite & 98.44 & $\mathrm{II} .54$ & 102.14 & 13.69 & 100.48 & 12.87 & 0.058 & - \\
\hline Flexibility & 96.09 & 12.40 & 99.87 & 14.35 & 98.17 & 13.60 & 0.07 & 0.20 \\
\hline Stress Tolerance & 98.80 & 13.33 & 103.56 & 12.86 & 101.42 & 13.25 & 0.02 & 0.059 \\
\hline Optimism & 101.09 & 11.49 & 101.61 & 14.38 & 101.37 & 13.13 & 0.79 & 0.99 \\
\hline Happiness & 100.81 & 10.77 & 101.18 & 11.92 & 101.01 & 11.39 & 0.83 & - \\
\hline
\end{tabular}

Abbreviations: $M$, mean; SD, standard deviation. 
Additionally, given our sample size and study design, it is likely our findings are correlational rather than causative.

\section{Conclusion}

Residents who had taken time off before matriculating in medical school had higher overall EI scores and higher scores in the EI components of interpersonal skill, empathy, decision-making, and impulse control. Residency program directors may consider interviewing or ranking an applicant more highly if the applicant has taken a gap year before starting medical school.

\section{Author Contributions}

Both authors made substantial contributions to conception and design, acquisition of data, or analysis and interpretation of data; took part in drafting the article or revising it critically for important intellectual content; agreed on the journal to which the article will be submitted; gave final approval of the version to be published; and agree to be accountable for all aspects of the work.

\section{Funding}

The authors report no external funding source for this study.

\section{Disclosure}

The authors report no conflicts of interest for this work.

\section{References}

1. Bradberry T, Greaves J. Emotional Intelligence 2.0. San Diego, CA: TalentSmart; 2009.
2. Weng HC. Does the physician's emotional intelligence matter? Health Care Manage Rev. 2008;33(4):280-288. doi:10.1097/01. HCM.0000318765.52148.b3

3. Mintz LJ, Stroller JK. A Systematic review of physician leadership and emotional intelligence. J Grad Med Educ. 2014;6(1):21-31. doi:10.4300/JGME-D-13-00012.1

4. Dugan JW, Weatherly RA, Girod DA, et al. A longitudinal study of EI training for Otolaryngology residents and faculty. JAMA Otolaryngol. 2014;140(8):720-726.

5. Chan K, Petrisor B, Bhandari M, et al. Emotional intelligence in ortho residents. Can J Surg. 2014;57(2):89-93. doi:10.1503/ cjs. 022512

6. McKinley S, Petrusa ER, Fiedeldey-van Dijk C, et al. A multi-institutional study of the emotional intelligence of resident physicians. Am J Surg. 2015;209(1):26-33. doi:10.1016/j. amjsurg.2014.09.015

7. Jensen AR, Wright AS, Lance AR, et al. The emotional intelligence of surgical residents: a descriptive study. Am J Surg. 2008;195 (1):5-10. doi:10.1016/j.amjsurg.2007.08.049

8. Shahid R, Stirling J, Adams W. Assessment of emotional intelligence in pediatric and med-peds residents. J Contemp Med Edu. 2016;4 (4):153-158. doi:10.5455/jcme.20170116015415

9. Gura T Mind the Gap Year. Available from: https://www.sciencemag. org/careers/2013/12/mind-gap-year. Accessed August 11, 2020. Accessed February 3, 2020.

10. Gap Year Association. Gap Year Data. Available from: https://www. gapyearassociation.org/data-benefits.php. Accessed August 11, 2020. Accessed February 3, 2020.

11. Bar-On R. Emotional Quotient Inventory 2.0 User's Handbook. Toronto Canada: Multi-Health Systems; 2004.

12. Goleman D. What makes a leader. Harvard Bus Rev. 1998;93-102.

13. Hoe $\mathrm{N}$ American gap association national alumni survey 2015 report. Available from: https://www.gapyearassociation.org/assets/2015\% 20NAS\%20Report.pdf.; 2015. Accessed February 3, 2020..

14. Paterson-Brown L, Paterson-Brown F, Simon E, et al. The influence of a 'gap year' on medical students. J Educ Training Stud. 2015;3 (4):49-56. doi:10.11114/jets.v3i4.810
Advances in Medical Education and Practice

\section{Publish your work in this journal}

Advances in Medical Education and Practice is an international, peerreviewed, open access journal that aims to present and publish research on Medical Education covering medical, dental, nursing and allied health care professional education. The journal covers undergraduate education, postgraduate training and continuing medical education including emerging trends and innovative models linking education, research, and health care services. The manuscript management system is completely online and includes a very quick and fair peer-review system. Visit http://www.dovepress.com/testimonials.php to read real quotes from published authors. 